\title{
Strategi Bisnis dalam Menghadapi Daya Beli Masyarakat yang Rendah pada Masa Pandemi Covid-19
}

\author{
Shadiqin Nawara, Ariful Fikri, Diki Rikardo \\ Program Studi Akuntansi, Fakultas Ekonomi dan Bisnis,Universitas Muhammadiyah Riau, \\ Email:180301195@student.umri.ac.id
}

\begin{abstract}
Pada masa pandemi Covid-19 saat ini memberikan tantangan baru bagi pelaku usaha yang ada di Indonesia.Perekonomian di Indonesia mengalami tekanan begitu berat pada saat ini.Sehingga pelaku usaha harus mampu beradaptasi dengan keadaan seperti ini.Penerapan Pricing-Strategies salah satu upaya untuk meningkatkan daya beli masyarakat terhadap produk yang dipasarkan.Strategi bisnis yang dilakukan agar mampu bertahan dengan kondisi seperti ini,maka perlu dilakukan perubahan harga pada produk.Perubahan harga yang dilakukan tentunya nanti akan memberikan pengaruh yang besar terhadap permintaan konsumen. Hasil pembahasan akan di implementasikan pada bisnis yang dijalankan pada masa pandemi ini.
\end{abstract}

Kata Kunci : Manajemen Strategis, Pricing-Strategies, Covid-19,Permintaan dan Penawaran,Ekonomi

\begin{abstract}
During the current Covid-19 pandemic, it presents new challenges for business actors in Indonesia. The economy in Indonesia is under so much pressure at the moment. So, business actors must be able to adapt to this kind of situation. The implementation of Pricing-Strategies is one of the efforts to improve people's purchasing power of the products being marketed. The business strategy that is carried out in order to be able to survive with conditions like this, it is necessary to change the price of the product. The price changes that are made will of course have a big influence on consumer demand. carried out during this pandemic.
\end{abstract}

Keywords: Strategic Management, Pricing-Strategies, Covid-19, Supply and Demand,Economic

\section{PENDAHULUAN}

Pada masa pandemi Covid-19 saat ini tidak hanya menyerang kesehatan,akan tetapi juga ikut menyerang keadaan ekonomi di Indonesia. Hal ini memberikan tantangan baru bagi para pelaku bisnis.Adanya tantangan baru didalam dunia bisnis,sehingga mengharuskan untuk bisa beradaptasi dengan situasi pada saat ini.Permasalahan yang terjadi di lingkungan bisnis saat ini yaitu menurunnya daya beli masyarakat terhadap produk yang ada di pasar.Ini terjadi akibat adanya kebijakan pemerintah untuk beraktivitas dirumah ( WFH ).Sehingga,banyak aktivitas operasional perusahaan yang tidak berjalan dan terhambat akibat adanya kebijakan beraktivitas dirumah ( WFH ).Dampaknya adalah banyak perusahaan yang mengalami kesulitan dalam memenuhi kewajibannya,dikarenakan tidak adanya akvitias operasional perusahaan.Salah satu upaya yang dilakukan banyak perusahaan yaitu melakukan pemutusan hubungan kerja ( PHK ), sehingga saat ini banyak sekali pengangguran.Tingginya tingkat pengangguran,mengakibatkan penurunan daya beli masyarakat.Masyarakat yang sedang menganggur cenderung meminimalisir pengeluaran keuangannya pada masa pandemi ini.Strategi bisnis yang perlu dilakukan ialah dengan melakukan perubahan harga dan memperhatikan permintaan dan penawaran terhadap produk.Ini bertujuan agar dapat menciptakan daya beli masyarakat terhadap produk yang 
ditawarkan.Dengan adanya penurunan harga tentunya nanti akan meningkatkan permintaan masyarakat terhadap produk di pasaran.

\section{Permintaan Dan Penawaran ( Supply And Demand)}

Secara Umum teori permintaan ( demand) dan penawaran ( supply ) dalam ilmu ekonomi adalah gambaran hubungan antara penjual-pembeli di pasar. Teori ini memberikan analisis terhadap perilaku konsumen di pasar.Harga berperan penting sebagai penyeimbang antara kuantitas yang diminta dan ditawarkan pada pasar.Sehingga,keseimbangan ekonomi antara harga dan kuantitas

Menurut Gregory Mankiw (2000) mengatakan bahwa pada penawaran, kuantitas yang ditawarkan berhubungan positif dengan harga barang. Kuantitas yang ditawarkan meningkat ketika harga meningkat dan menurun ketika harga menurun. Hubungan antara harga dan kuantitas yang ditawarkan ini dinamakan hukum penawaran (law of supply) dengan menganggap hal lainnya sama, ketika harga barang meningkat,maka kuantitas barang tersebut yang ditawarkan akan meningkat

Menurut Nopirin (1994)kuantitas yang diminta akan menurun ketika harganya meningkat dan kuantitas yang diminta meningkat ketika harganya menurun, dapat dikatakan bahwa kuantitas yang diminta berhubungan negatif (negatively related) dengan harga.

\section{Strategi Penetapan Harga ( Pricing-Strategies )}

Penetapan harga sangat berperan penting didalam dunia bisnis. Harga sangat mempengaruhi permintaan dan penawaran terhadap produk di pasar.Maka dari itu perlu strategi didalam penetapan harga yang terbaik.Penetapan harga bertujuan untuk :

- Memaksimalkan Keuntungan Laba

- Mempertahankan Pasar

- Melakukan Stabilitas Harga

- Menjaga Kelangsungan Bisnis

Strategi dalam menetapkan harga yang terbaik yaitu :

1) Penetapan harga berdasarkan pendekatan biaya ( Cost Oriented Pricing ).

Cara ini menetapkan harga produk dengan menjumlahkan biaya total + laba = harga jual

2) Penetapan harga berdasarkan pendekatan kebutuhan dan permintaan.

Menurut Djaslim Saladin (2003:96) penentuan harga dengan mempertimbangkan

keadaan permintaan, keadaan pasar dan keinginan konsumen. Demand-oriented

pricing mendasarkan kepada tingkah laku demand, misalnya harga tinggi

apabila demand sangat kuat dan harga rendah bilamana demand lemah.

3) Penetapan harga berdasarkan pendekatan persaingan ( Competition Oriented Pricing ).

Cara ini menetapkan harga produk dengan mengikuti harga para pesaing di pangsa pasar.

\section{METODE}

Metode yang digunakan dalam penelitian ini adalah metode kuantitatif.Penelitian dilakukan dengan menggunakan data perubahan harga jual pada produk. Data yang diperoleh nantinya akan diolah dengan cara matematis melalui regresi linier sederhana.Menggunakan rumus matematis $Y=a+B(x)$. Siubi merupakan salah satu pelaku usaha umkm di Kota Pekanbaru yang aktivitasnya adalah memproduksi makanan.Data diperoleh secara langsung dari pelaku usaha umkm Siubi yang berlokasi di Indonesia,Kota Pekanbaru,Riau.

\section{HASIL DAN PEMBAHASAN}

Data perubahan harga dan pengaruhnya terhadap daya beli masyarakat pada masa pandemi Covid-19.Data bersumber dari pelaku usaha umkm Siubi,Indonesia, Kota Pekanbaru,Riau.

\begin{tabular}{l|l} 
Harga (X) & Permintaan ( Y )
\end{tabular} 


\begin{tabular}{|c|c|}
\hline Rp.15.000 & 100 \\
\hline Rp.13.000 & 125 \\
\hline Rp.10.000 & 200 \\
\hline
\end{tabular}

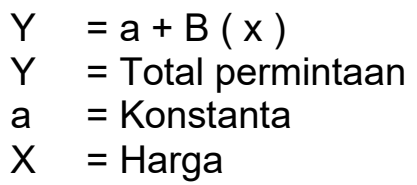

\begin{tabular}{|l|l|l|l|l|l|}
\hline $\mathrm{N}$ & $\mathrm{X}$ & $\mathrm{Y}$ & $\mathrm{XY}$ & $\mathrm{X}^{2}$ & $\mathrm{Y}^{2}$ \\
\hline 1 & 15.000 & 100 & 1.500 .000 & 225.000 .000 & 10.000 \\
\hline 2 & 13.000 & 125 & 1.625 .000 & 169.000 .000 & 15.625 \\
\hline 3 & 10.000 & 200 & 2.000 .000 & 100.000 .000 & 40.000 \\
\hline$\sum 3$ & $\sum 38.000$ & $\sum 425$ & $\sum 5.125 .000$ & $\sum 494.000 .000$ & $\sum 65.625$ \\
\hline
\end{tabular}

\section{Hasil Penelitian}

Menghitung nilai $b$ atau koefisien regresi

$$
\begin{aligned}
\mathrm{b} & =\frac{\mathrm{n}\left(\sum x y\right)-\left(\sum x\right)\left(\sum y\right)}{\mathrm{n}\left(\sum \mathrm{x}^{2}\right)-\left(\sum \mathrm{x}\right)^{2}} \\
\mathrm{~b} & =\frac{3(5.125 .000)-(38.000)(425)}{3(494.000 .000)-(38.000)^{2}} \\
\mathrm{~b} & =\frac{15.375 .000-16.150 .000}{1.482 .000 .000-1.444 .000 .000} \\
\mathrm{~b} & =\frac{-775.000}{38.000 .000} \\
\mathrm{~b} & =-0,02
\end{aligned}
$$

Menghitung konstanta atau intercept

$$
\begin{aligned}
& a=\frac{\left(\sum y\right)\left(\sum x^{2}\right)-\left(\sum x\right)\left(\sum x y\right)}{n\left(\sum x^{2}\right)-\left(\sum x\right)^{2}} \\
& a=\frac{(425)(494.000 .000)-(38.000)(5.125 .000)}{3(494.000 .000)-(38.000)^{2}} \\
& a \quad=\frac{209.950 .000 .000-194.750 .000 .000}{1.482 .000 .000-1.444 .000 .000} \\
& a \quad=\frac{15.200 .000 .000}{38.000 .000} \\
& a \quad=400
\end{aligned}
$$

Pengujian penelitian dengan menetapkan harga Rp.8.000.

$$
\begin{aligned}
& Y=400+-0,02(8.000) \\
& Y=400+-160 \\
& Y=240
\end{aligned}
$$

\begin{tabular}{|c|c|}
\hline Harga $(X)$ & Permintaan $(\mathrm{Y})$ \\
\hline 15.000 & 100 \\
\hline 13.000 & 125 \\
\hline 10.000 & 200 \\
\hline 8.000 & 240 \\
\hline
\end{tabular}




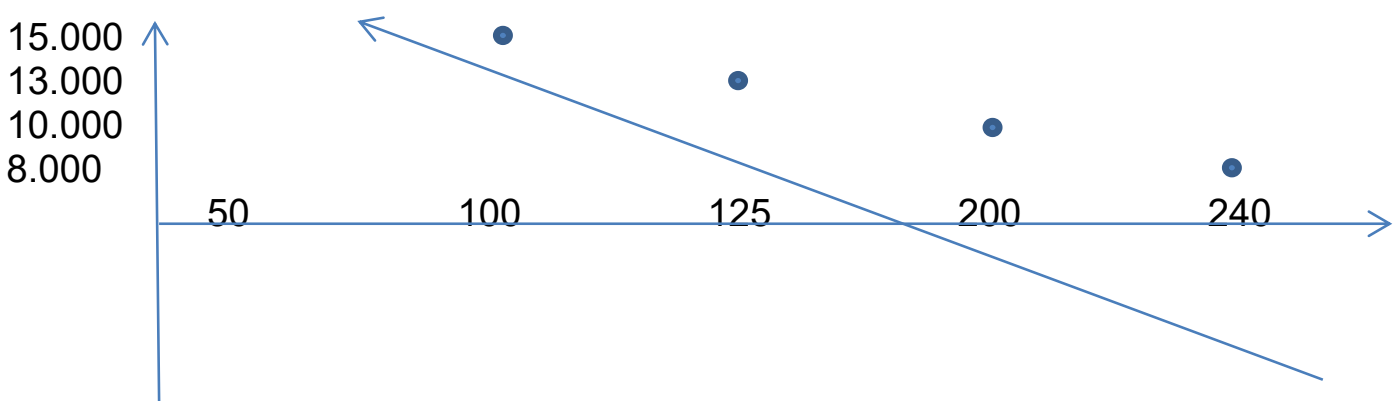

\section{Pembahasan}

Nilai Koefisien $(b)$ memperoleh nilai negatif sebesar 0,02.Artinya adalah jika variable $\mathrm{X}$ bertambah maka nilai $\mathrm{Y}$ akan turun/berkurang.

Penelitian ini menunjukkan bahwa,harga sangat mempengaruhi terhadap permintaan produk di pasar.Jika harga $(X)$ bertambah,maka permintaan ( $Y$ ) akan menurun.Permasalahan yang dihadapi pada masa pandemi Covid-19 ini ialah terjadinya penurunan daya beli masyarakat.Maka dari itu strategi seperti penurunan harga ini akan membantu meningkatkan daya beli masyarakat terhadap produk.Dari hasil penelitian,dapat disimpulkan jika harga ( $X$ ) meningkat,maka permintaan ( $Y$ ) menurun.Dan jika harga menurun ( $X$ ), maka permintaan ( $Y$ ) akan meningkat.

Berdasarkan grafik data diatas,hubungan antara variabel $X$ dan $Y$ itu berbanding terbalik atau negatif.Dapat disimpulkan bahwa,jika harga meningkat maka permintaan akan menurun.Dan jika harga menurun maka permintaan meningkat.

\section{KESIMPULAN}

Berdasarkan hasil penelitian mengenai strategi bisnis dalam menghadapi daya beli masyarakat yang rendah pada masa pandemi Covid-19 ini ,dapat disimpulkan bahwa harga sangat mempengaruhi permintaan atau daya beli masyarakat.Jika harga dinilai terlalu tinggi,maka permintaan cenderung akan menurun.Dan sebaliknya jika harga dinilai terlalu rendah,maka permintaan cenderung akan meningkat.Saat ini,situasi mengalami tekanan yang cukup berat.Upaya yang dapat dilakukan untuk bisa meningkatkan daya beli masyarakat yaitu dengan melakukan perubahan harga yang lebih kecil dari sebelumnya. Hal ini dibuktikan dengan dilakukannya analisis matematis regresi linier berganda pada hasil penelitian dan pembahasan.

Berdasarkan hasil penelitian diatas.Perubahan harga jual produk yang terbaik yaitu terletak di harga Rp.8.000.Dari hasil penelitian,jika harga Rp.8.000 maka permintaan menjadi sebesar 240 unit.Penelitian ini diharapkan dapat berguna bagi pelaku usaha umkm Siubi didalam mengahadapi rendahnya daya beli masyarakat pada masa pandemi Covid-19 ini.

\section{DAFTAR PUSTAKA}

Statistik Edisi 8 jilid 2. (2016). Erlangga.

Abdul Narlan, D. T. ( 2018). statistika dalam penjas aplikasi praktis dalam penelitian pendidikan jasmani.

Asauri, S. (2009). Manajemen Pemasaran. Jakarta.

Blocher, E. J. (2007). Cost Management. Salemba, Buku Satu, Edisi Ketiga,Jakarta: Salemba Empat.

Carter, W. K. ( 2006). Cost Accounting. Edisi Ketigabelas, Jakarta:.

Fajriansyah, I. d. (n.d.). Manajemen Strategik.

Garrison, R. H. (2006). Managerial Accounting, 11th Edition. Jakarta: Salemba Empat.

Gitiyarko, V. (2020). Upaya Kebijakan Pemerintah Indonesia Menangani Pandemi Covid-19. Jakarta: Kompas.

Kalangi, J. B. (n.d.). Matematika Ekonomi Dan Bisnis. Jakarta: Salemba Empat.

Kuncoro, M. (2004). Accounting Management. Jakarta: Salemba Empat. 
Nicholson, W. (2005). Microeconomic Theory, Basic Principles and Extension. Thomson South Western, Ohio.

Prof. Dr. Sofjan Assauri, M. (n.d.). strategic Management.

Sukirno, S. (n.d.). Pengantar Teori Ekonomi Mikro. Jakarta: PT. Raja Grafindo. 